\title{
Development of Reconfigurable Antenna for Advanced Tracking Technology
}

\author{
N.M. Sahar*, M.T Islam, N. Misran, M.R Zaman \\ Electronic \& Electrical Engineering Programme, Faculty of Engineering \& The Built Environment, \\ SEGi University
}

\section{Article Info \\ Article history: \\ Received Nov 29, 2017 \\ Revised Jan 28, 2018 \\ Accepted Feb 17, 2018}

\section{Keywords:}

GPS

MEMS switches

Multiband antenna

Reconfigurable antenna

RFID

\begin{abstract}
This paper focuses on the design and fabrication of reconfigurable multiband antenna for RFID and GPS as an advance tracking technology for various applications that achieve a physically compact, planar profile and sufficient bandwidth. The antenna can be reconfigured as single band at $1.275 \mathrm{GHz}$ for GPS applications when the switches are OFF state and dual-band frequencies at $0.915 \mathrm{GHz}$ and $2.4 \mathrm{GHz}$ required in RFID applications when the switches are $\mathrm{ON}$ state. The performance of the antenna involves changing the switches to ON or OFF mode by controlling RF switches. RF MEMs RMSW101, Single Pole Single Throw (SPST) switches have been chosen due to the satisfactory RF properties includes low insertion loss, good impedance matching and high isolation. The gain for single and dual band is greater than $2 \mathrm{dBi}$. The design methodology and antenna measurement results are both presented and discussed in this letter.
\end{abstract}

Copyright $\odot 2018$ Institute of Advanced Engineering and Science. All rights reserved.

\section{Corresponding Author:}

N.M. Sahar,

Electronic \& Electrical Engineering Programme,

SEGi University,

47810 Petaling Jaya, Selangor, Malaysia.

Email: norsuzlinsahar@segi.edu.my

\section{INTRODUCTION}

The development of reconfiguration antenna is relying on the application areas include multipleinput multiple-output (MIMO), ultra wideband system and multifunction wireless devices [1]. To meet the needs of systems presents several difficulties include when restricting reconfiguration to a specific aspects of the antenna performance. Besides, the implementation and control the reconfiguration mechanism also face the challenges. Various mechanism enables the changes in the antenna impedance and/or radiation properties such as material tuning, structural modifications and switching. By controlling the system, the desired antenna performance can be applied. Reconfigurable antennas are useful to support different standards in mobile and satellite communications that can overcome strong interference signal and manage changing operational environment. [2]-[8]. RFID and GPS provide vast potentials in helping ease many aspects of our daily tasks. These include tracking solutions not only for our personal work but also benefits some aspects of environmental work. This is because the RFID system can be used in tagging and GPS as tracking.

For reconfigurable multiband antenna for RFID and GPS applications as handheld device, the antenna must be of low profile, compact size, light weight, low cost and conformable to the architecture of the mounting device. It has the advantage of low profile in size, compactness and easily integrate with RF circuitry. In this letter, two types of antennas have been developed in order to meet requirement of reconfigurable multiband antenna for RFID and GPS applications. All these antennas are simulated, measured and discussed. RFID and GPS has a big potential in helping many aspects as tracking solution for our personal and work environmental as provide safety to people and cargo and also increase the efficiency of a system. RFID as away to identify individual item or person. The RFID tag as a substitute for the existing 
bar cord, recognizes, modifies and tracks information through microchips mountable on an antenna. GPS as together with the tracker device able to determine the precise location in geographically of vehicles, person or other asset. Other advantages are able to record the position asset at regular intervals. This advance tracker RFID and GPS wide application such as for public transport for security of passenger and enhance the service.

With the rapid development of Radio Frequency Identification technology in service industries and commercial wireless applications, many papers were presented in the literature. Most of RFID antennas were designed to operate at one or more frequency bands, Low Frequency, High Frequency, Ultra High Frequency, and Microwave. Each of frequency bands has their own advantages. Thus, the urge of multiband RFID antennas is becoming vivid. As a result, there are many papers were designed a multiband antenna for RFID applications which was applicable for several standards [9]. Due to different worldwide regulations, the frequency bands have different locations in the spectrum. For an example is UHF- RFID application, Europe operates at 855-869 MHZ, US at 902-928 MHz and Japan 950-928 MHz [10]. Moreover, ISM-RFID operates at $2.45 \mathrm{GHz}$ and $5.8 \mathrm{GHz}$. In this paper, a simple structure antenna operating as single band for GPS application and dual band, UHF and ISM bands for RFID applications is proposed. The C-shaped patches perform as a radiating element is loaded with a basic dipole antenna to achieve a dual band antenna is presented. The optimized antenna is prototyped and tested for verification. The methodology as well as discussions on both simulation and measurement is presented in the subsequent sections.

\section{ANTENNA DESIGN}

The proposed antenna is designed on a Fire Retardant-4 board (FR4) with the dimension of 120 x 60 $\mathrm{mm}^{2}$ in size which has a relative dielectric constant of $\varepsilon_{\mathrm{r}}=4.7$ with tangent loss of 0.019 and it has a $1.6 \mathrm{~mm}$ substrate thickness and a $0.035 \mathrm{~mm}$ copper thickness. A planar dipole antenna is designed as the basic antenna resonating as single band when the switches are OFF state. The C-shaped patches perform as a radiating element is loaded with a basic dipole antenna by using MEMS switches to achieve a dual band antenna. The proposed antenna uses a single substrate and no ground plane is required.

The parameters of $w_{1}, w_{2}, w_{3}$ and $w_{4}$ have been selected to optimize the performance of frequency resonant, bandwidth and circular polarization for GPS applications which is $1.27 \mathrm{GHz}$. The changes of $w_{1}$ do not affect the frequency resonance, return loss and bandwidth but varying the axial ratio. The parameter of slot $g_{5}$ and $g_{6}$ are unequal because the space needs to be considered for biasing the MEMS switches. The different slotted does not change the return loss and resonant frequencies.

\subsection{Single Band Antenna for GPS Applications}

The planar dipole antenna is a low profile as it is producing on printed circuit board and also easily integrated directly to the RF circuit. The arm length of dipole can be calculated based on the operating frequency value. However, there are challenges in designing a dipole antenna for circular polarization. GPS use circular polarization antenna because it is more tolerent with physical orientation mismatches. Also CP provides for reduction in multipath effects and flexibility in the orientation angle between a transmitter and a receiver [11].

Asymetrical dipole also influence the CP result. [12] proposed a pair of unequal arm with a small gap which is fed by an L-shaped microtrip feedline through a via to ensure the orthogonal surface current have a appropriate phase for circular. Asymetrical crossed dipole has been proposed [13] by arranging the position of the unequal lentgh for arms, the sense of CP radiation can be obtained. Therefore, to determine the frequency resonance, length $w_{4}$ which is arm length of dipole can be calculated. This is proven from the current distribution in Figure 1. The current is strongly distributed along $w_{2}$ and $w_{4}$.

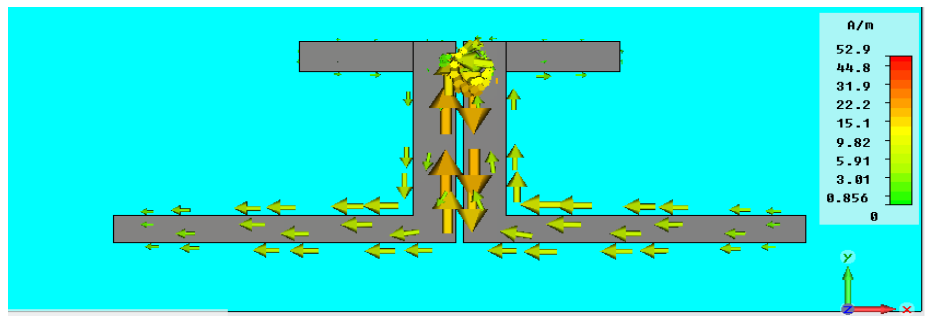

Figure 1. Current distribution without C-shaped patches at $1.2775 \mathrm{GHz}$ 


\subsection{Dual Band Antenna for RFID Applications}

The folded dipole antenna loaded with the C-shaped patch is proposed. The configuration of Cshaped patch is inspired from the design existance of E-shaped antenna. When the C-shaped loaded with arm length of dipole, the current distribution is exactly like E-shaped patch antenna at center fed. To meet the requirement of dual band of RFID applications including circular polarization and the impedance bandwidth, E-shaped design has that ability. As dipole loaded with $\mathrm{C}$-shaped patch antenna, the concept of E-shaped patch antenna is studied. Typically, the E-shaped patch antenna was presented in literature for dual resonance [14]-[15] and wideband [16]-[17], due to the slot dimensions that was introduced in patch. When the switches are $\mathrm{ON}$ state, the $\mathrm{C}$-shaped patches are integrated with the folded dipole. Thus, both radiating elements are connected to assume the performance of dual band. By not changing the parameters of folded dipole, the parameter of $a, b, c$ and $d$ are varied to optimize the result for RFID applications.

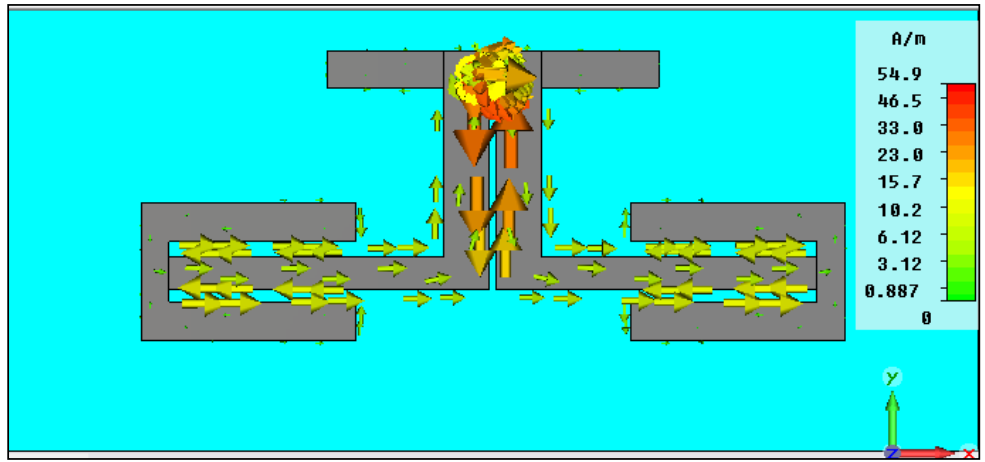

Figure 2. Current Distribution at Lower Band at $0.915 \mathrm{GHz}$

For lower band of the proposed antenna, parameter of $a$ has a large effected as the slot width increase, the current path is also increased and the resonant frequency decreased. The reduction of length $L_{1}$ is caused by adding the length of $w_{3}$ as shown in Figure 2. The current distribution is along the length of $w_{3}$ and $w_{4}$. In optimising the upper band of the proposed antenna, the parameter of $b, c$ and $d$ are varied without effect the lower band result. As depicted on Figure 3, the high current has flowed around the slot corner. Parameter $d$ also influenced the upper band frequency by increasing the length as the design has added from the length $w_{l}$. However, the small current has distributed along the length $c$. The change of length $\mathrm{c}$ is reflected to optimize the resonant frequency at lower band.

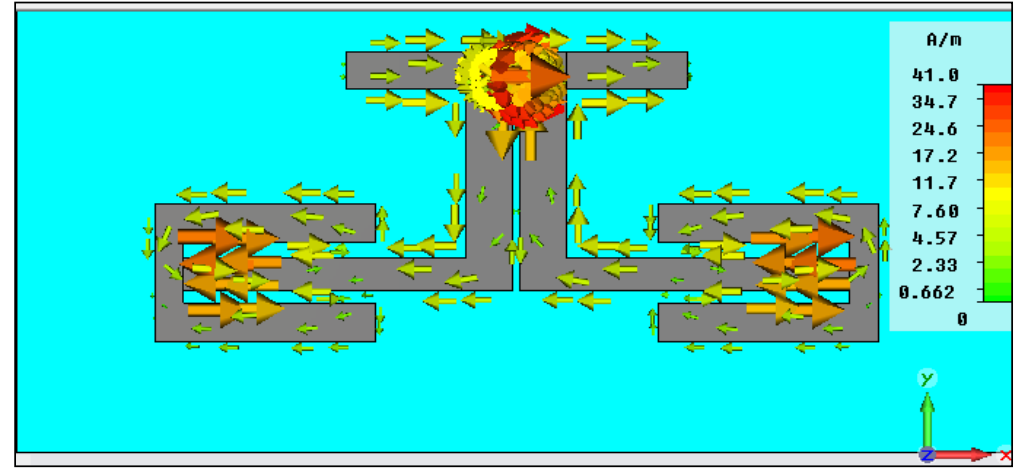

Figure 3. Current Distribution at Upper Band, $2.4 \mathrm{GHz}$

Based on the requirement of proposed antenna, the circular polarized also need to be design for $1.2275 \mathrm{GHz}$ and $0.915 \mathrm{GHz}$. An asymmetry slot has been introduced $g_{5}$ and $g_{6}$ which are $2 \mathrm{~mm}$ and $1.5 \mathrm{~mm}$ respectively as to adjust a better axial ratio less than $3 \mathrm{~dB}$. For $g_{3}$ and $g_{4}$, both have same values that are 4.75 $\mathrm{mm}$. To design a reconfigurable multiband antenna, a gap between folded dipole and $\mathrm{C}$-shaped patch is 
identified to place the RF MEMS switches. As depicted in Figure 4, the reconfigurable antenna design is proposed

Table 1. Optimized Parameters of the Proposed Reconfigurable Antenna

\begin{tabular}{cccc}
\hline Parameter & Value $(\mathrm{mm})$ & Parameter & Value $(\mathrm{mm})$ \\
\hline$L$ & 120 & $b$ & 23 \\
$W$ & 60 & $c$ & 17 \\
$L_{I}$ & 87 & $d$ & 26.5 \\
$W_{I}$ & 4 & $g_{1}$ & 14.5 \\
$w_{1}$ & 20 & $g_{2}$ & 3.5 \\
$w_{2}$ & 4.5 & $g_{3}$ & 4.75 \\
$w_{3}$ & 21 & $g_{4}$ & 4.75 \\
$w_{4}$ & 39.5 & $g_{5}$ & 2 \\
$A$ & 7.5 & $g_{6}$ & 1.5 \\
\hline
\end{tabular}

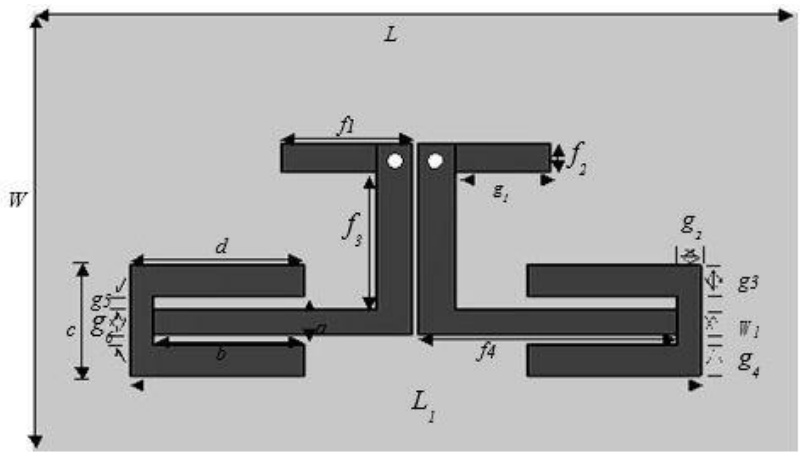

Figure 4. The Proposed Reconfigurable Antenna

\subsection{Reconfigurable Antenna Using RF MEMs Switches}

To design a reconfiguraable multiband antenna, a gap between folded dipole and C-shaped patch is identified to place the RF MEM S switches. The $1.55 \mathrm{~mm}$ gap is introduced between the folded dipole and $\mathrm{C}$-shaped patch antenna. The changges are done on length $f_{4}$ that is decreased to $37.95 \mathrm{mmm}$ and resulted different resonant frequency at $1.28 \mathrm{GHz}$. Even though the length $w_{4}$ has disturbed the resonant frequency for GPS, the optimization would be done by design a copper pad between the patches. Copper pad size $1 \mathrm{~mm}^{2}$ is designed closer to the patch 2 because to avoid the smaller coupled line with the patch 1 . The smaller the coupled line within the patches, the electric current is induced within the coupling conductors [18]. This definitely will interrupt the resonant frequency. Thus, the adjustment is made by moving the copper nearer to the patch two. Therefore, the gap between the patch 1 and the copper pad is $0.4 \mathrm{~mm}$. However, others parameter is remained. Another copper pad $0.6 \mathrm{~mm} \times 0.4 \mathrm{~mm}$ in size as DC bias line has design to connect the 90 VDC to MEMS gate. The wire is connected underneath the substrate and connected with coppper line $1.3 \mathrm{~mm} \times 0.15 \mathrm{~mm}$ in size as depicted in Figure 5. The copper line should not be drawn along the length $b$ because the performance will be affected as the slots are very important to perform dual band and the circular polarised antenna.

In designing the reconfigurable antenna, coaxial feed is preferred as to reduce the spurious radiation when the switches are place on the patches. The fabrication is easily done because of the FR4 substrate has $1.6 \mathrm{~mm}$ thickness. The ground plane is not required where the outer conductor of the coaxial cable is connected with the right arm of dipole via a copper wire while the inner conductor goes through the substrate to the left arm length of dipole antenna as shown in Figure 6. 


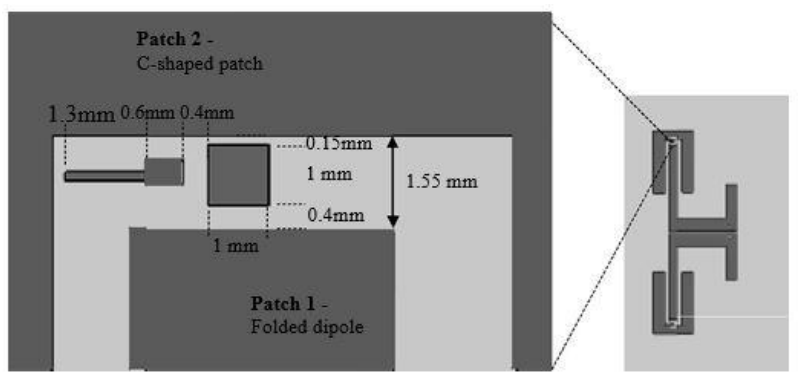

Figure 5 Configuration of Copper Pad to Place RF MEMS Switch

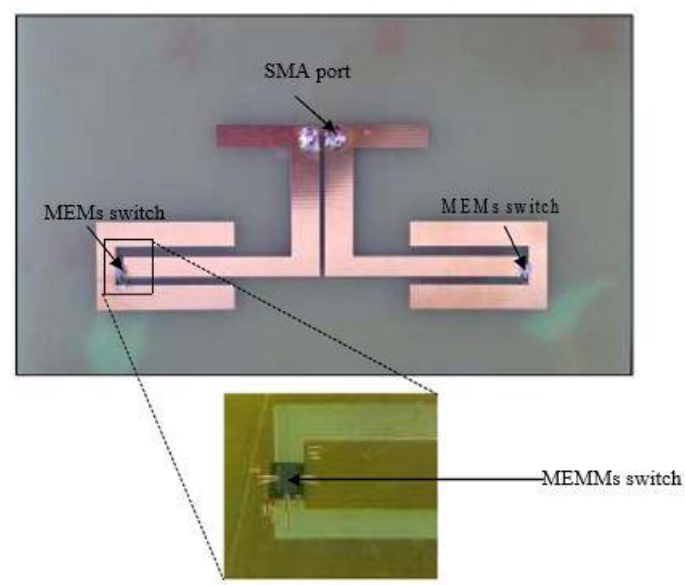

Figure 6. MEMs Switches Wire Bonded on the Proposed Antenna

The design section helped defined the dimensions of the antenna during the initial stage for dipole antenna and when the dipole loaded with the patches. The optimisation of the the antenna structure was then carried out by electromagnetic computation. In hardware design, prototype develope ment and fabrication of the Radant MEMS SPST-RMSW 101 switches were explained.

For experimental work, the DC-DC converter is required because of the actuation voltage for the MEMS switches are 90 VDC. The device behaves as $50 \mathrm{ohm}$ microstrip transmission line in the actuated state. Therefore $5 \mathrm{~V}$ power suppply is connected to the DC-DC converter. The switch is connected between the equipments to practically con duct the MEMS switches during the experiment where the switches are $\mathrm{OFF}$ when $5 \mathrm{~V}$ is not supplied. MEM S switches are $\mathrm{ON}$ state when the switch is closed and $5 \mathrm{~V}$ is supplied to DC-DC converter.

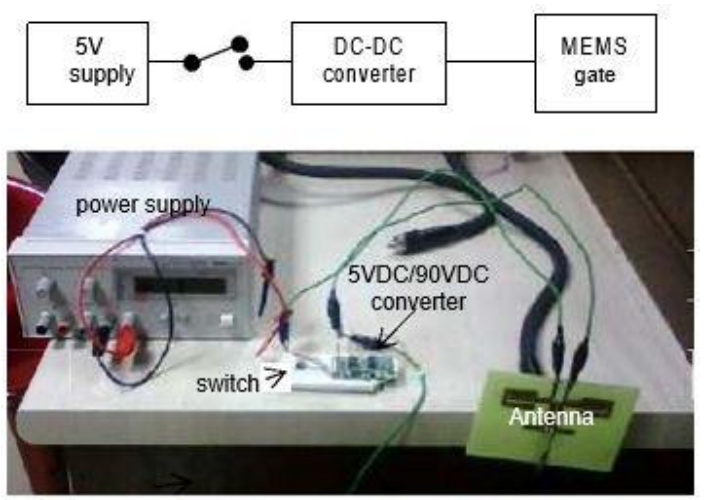

Figure 7. The Connection of Proposed Antenna for Experimental Work 
The measurement configuration of proposed antenna is shown in Figure 7. The performance of Sparameter is measured by Network Analyzer after the prototype is fabricated. This result is compared to validate the simulation and to verify the technical specification. For radiation characteristics measurements, the antennas have been measuredd in an anechoic chamber using far field antenna measurement equipment.

\section{RESULTS AND ANALYSIS}

According to simulated reflection coefficient at $1.2275 \mathrm{GHz}$ is $-19.52 \mathrm{~dB}$ and the bandwidth is $170 \mathrm{MHz}$. However, the measured reflection coefficient curve of the proposed antenna is excited at $1.23 \mathrm{GHz}$ with a $-22.37 \mathrm{~dB}$. The bandwidth of measured value is greater than simulated result which is about $280 \mathrm{MHz}$ satisfies the $(<-10 \mathrm{~dB})$ when the switches are OFF state as shown in Table 2 . The bandwidth difference percentage is about $39.2 \%$ as shown in Figure 8. The simulated gain and directivity of the proposed antenna are $2.104 \mathrm{dBi}$ and $2.44 \mathrm{~dB}$ respectively as shown in Figure 9(a)(b). The axial ratio of the proposed antenna when the switches are OFF is 0.928 which is performed as circular polarisation and $98 \%$ of antenna efficiency. A proposed dual-band antenna is performed when the switches are ON state. Based on the Table 3 , the lower band of measured reflection coefficient is excited at $0.87 \mathrm{GHz}$ with $-13.4 \mathrm{~dB}$ return loss.

The percentage of differences between simulated and measured resonant frequency is $4.9 \%$ where simulated frequency resonance is $0.915 \mathrm{GHz}$ at $-12.7 \mathrm{~dB}$ of reflection coefficient For the upper band, the simulated frequency resonance of the proposed antenna is $2.4 \mathrm{GHz}$ with $-18.32 \mathrm{~dB}$ return loss. However, the measurement result of operating frequency performed $8.3 \%$ far from the simulated result. Due to effect of switches and SMA connector soldering and fabrication tolerances, the upper band excited at $2.6 \mathrm{GHz}$ with return loss is $-23.67 \mathrm{~dB}$ of measurement value. The bandwidths for lower and upper bands are $57 \mathrm{MHz}$ and $500 \mathrm{MHZ}$ respectively. As compared with the simulated bandwidth, measured dual band bandwidths are greater with the percentages are 5\% and 52.8\% as seen in Figure 8(b). The gain of lower band is $2.19 \mathrm{dBi}$ and the directivity is $2.21 \mathrm{~dB}$. However, the gain and directivity for the upper band is greater than lower band which is $7.33 \mathrm{dBi}$ and $7.252 \mathrm{~dB}$ respectively as depicted in Figure 9. As requirement, the lower band is performed circular polarisation with axial ratio at 2.52. Meanwhile the upper band of axial ratio is 25.51. The antenna efficiency at lower band is $69 \%$ and for upper band is $89.1 \%$.

Table 2. Comparison Result of Single Band

\begin{tabular}{ccc}
\hline When switches are OFF state & Simulated result & Measured Result \\
\hline Frequency Resonance $(\mathrm{GHz})$ & 1.2275 & 1.23 \\
Reflection coefficient $(\mathrm{dB})$ & -19.52 & -22.37 \\
Bandwidth $(\mathrm{GHz})$ & $1.21-1.38$ & $1.09-1.37$ \\
\hline
\end{tabular}

Table 2. Comparison Result of Dual Band

\begin{tabular}{ccccc}
\hline \multirow{2}{*}{ When switches are ON state } & \multicolumn{2}{c}{ Simulated result } & \multicolumn{2}{c}{ Measured Result } \\
& Lower Band & Upper Band & Lower Band & Upper Band \\
\hline Frequency Resonance $(\mathrm{GHz})$ & 0.915 & 2.46 & 0.87 & 2.6 \\
Reflection coefficient $(\mathrm{dB})$ & -12.7 & -18.32 & -13.4 & -23.67 \\
Bandwidth $(\mathrm{GHz})$ & $0.87-0.93$ & $2.33-2.57$ & $0.85-0.91$ & $2.43-2.93$ \\
\hline
\end{tabular}

Secondly, the radiation patterns of E-plane and H-plane patterns are discussed to describe the performance of the antennas. The E-plane contains electric field vector and direction of maximum radiation. On the other hand, the plane that contains a magnetic field vector and direction of maximum radiation is the H-plane. The radiation patterns of different states are shown in Figure 9. It is observed that the patterns resulted from the measurements have many ripples in amplitude due to many reflections into the field between the AUT and reference antenna. The reflections may come from the room floor and ceiling, chamber scattering and track inside the anechoic chamber. 


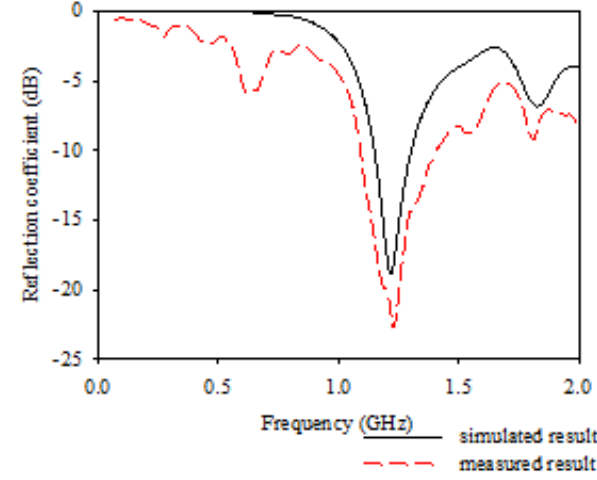

(a)

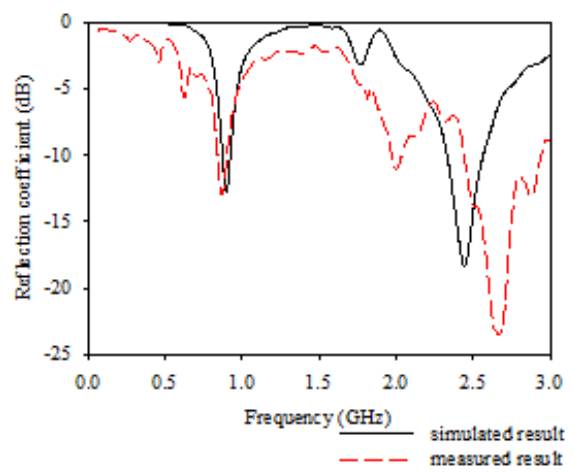

(b)

Figure 8. Comparison Simulated and Measured Return Loss of Prototype Antenna when MEMs Switches (a) ON State(b) OFF State

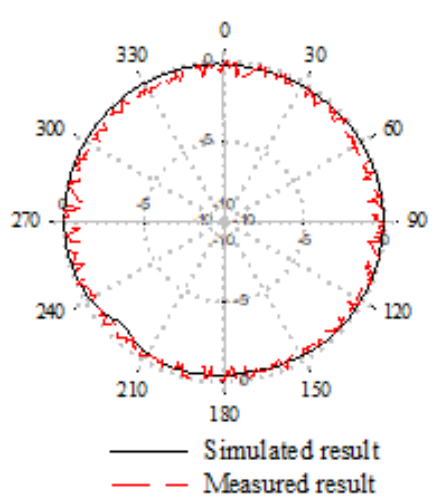

(a)

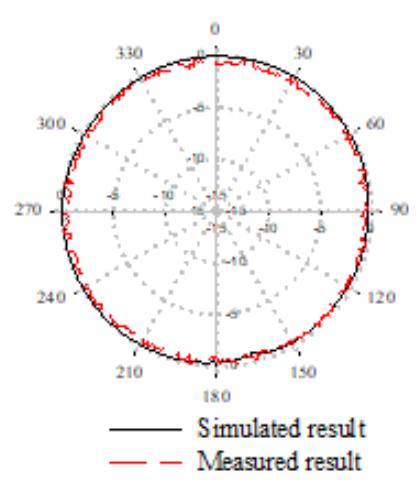

(b)

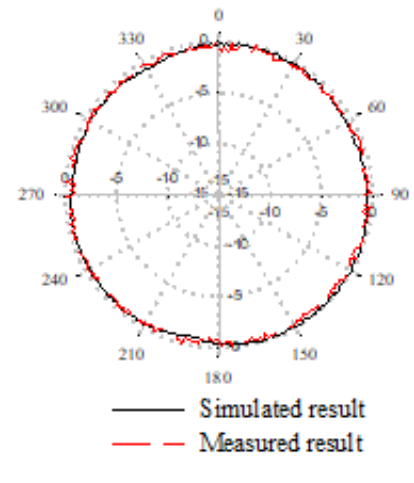

(c)

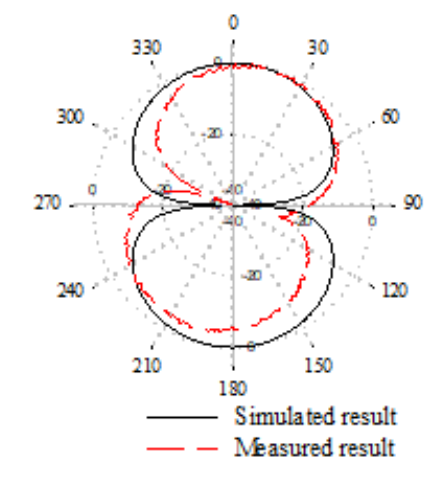

(d)

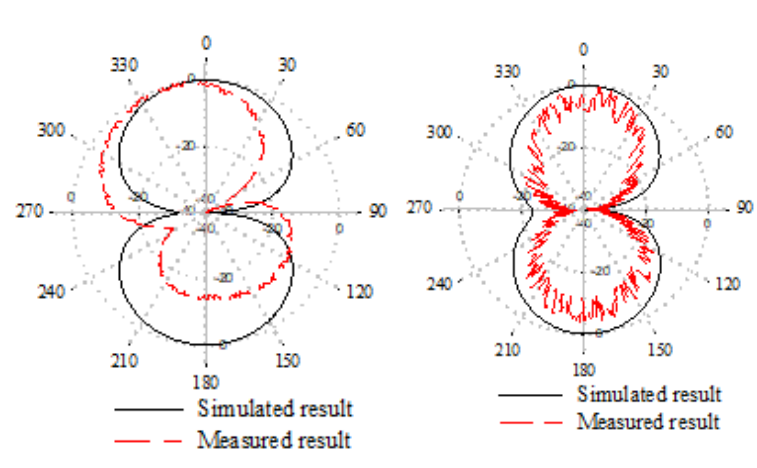

(e)

(f)

Figure 9. Comparison Simulated and Measured Radiation Patterns of Prototype Antenna (a) H-Plane at 1.27 $\mathrm{GHz}$ (b) E-Plane at $1.27 \mathrm{GHz}$ (c) H-Plane at $0.915 \mathrm{GHz}$ (d) E-Plane at $0.915 \mathrm{GHz}$ (e) H-Plane at 2.45GHz (f) E-Plane at $2.45 \mathrm{GHz}$

\subsection{Read Range}

To measure the read range distance that is more practical, outdoor measurement is preferable. By exposed the proposed antenna with the real environment and noise can challenge the performance. Firstly, the input power of $32.5 \mathrm{dBm}$ and the antenna port need to be set up reader settings for the proposed antenna radiates. The sample of RFID antenna is connected to the reader device at port two using RF cables. The 
reader device is connected to the computer and network. When the power supply is connected, the light on the reader device is turned on and others are blinked as indication of functionality. Once logged into the reader, the IP address is appeared in the command line interface by moving the tag 1 meter steps. As a result, the dipole loaded with the $\mathrm{C}$-shaped antenna read range is found to be 16 meters.

\section{CONCLUSION}

The C-shaped patch loaded with dipole antenna is being proposed. This design will be able to reconfigure the frequency band of the antenna by switches in controlling the current flow through the radiating C-shaped patches. A single dipole is operated when the switches are OFF excited at $1.2275 \mathrm{GHz}$ for GPS application. The dual-band frequency is performed at $0.915 \mathrm{GHz}$ and $2.4 \mathrm{GHz}$, UHF and ISM bands for RFID applications when the switches are ON state. The simulation of the radiation pattern gives an omnidirectional pattern for both single band and dual bands. The proposed antenna has been fabricated and tested and it showed good agreement between simulated and measured results.

\section{REFERENCES}

[1] Ammar Alhegazi, Zahriladha Zakaria, Noor Azwan Shairi, Tole Sutikno, Sharif Ahmed, "UWB Filtenna with Electronically Reconfigurable Band Notch using Defected Microstrip Structure," Indonesian Journal of Electrical Engineering and Computer Science(IJEECS), vol 8, No 2: 2017.

[2] Wu Liu,.-L., Chen, T.-R., Chen, S.-H. \& Row, J.-S.., "Reconfigurable microstrip antenna with pattern and polarisation diversities," Electronics Letters. vol. 43(2), pp. 77-78, 2007.

[3] Mak, A.C.K., C. R. Rowell, R. D. Murch, \& Chi-Lun Mak, "Reconfigurable Multiband Antenna Designs for Wireless Communication Devices," Antennas and Propagation, IEEE Transactions, vol. 55(7), pp.1919-1928, 2007.

[4] Youn-Kwon Jung \& Lee, B., "Dual-Band Circularly Polarized Microstrip RFID Reader Antenna Using Metamaterial Branch-Line Coupler," IEEE Transactions on Antennas and Propagation, vol.60(2), pp.786$791,2012$.

[5] Chun Ni, et al., "Design of Frequency and Polarization Reconfigurable Antenna Based on the Polarization Conversion Metasurface," in IEEE Antennas and Wireless Propagation Letters, vol PP(99)pp. 1-1, 2017.

[6] Omar El Maleky, Farid Ben Abdelouahab, Mohammad Essaaidi, Nasri Abdelfatah, "Miniature design of T-Shaped frequency Reconfigurable antenna for S-Band Application using Switching Technique," International Journal of Electrical and Computer Engineering (IJECE), vol 7, no 5: 2017.

[7] Zhu Anshi, Chen Zili, Wei Jianbin, Zhen Yunhui, "Study on Pattern Reconfiguration of Plasma Antenna Excited by Surface Wave," Indonesian Journal of Electrical Engineering and Computer Science(IJEECS), vol 12, no 9: 2014.

[8] Arrauzah Razak, M. K. A. Rahim, H. A. Majid, N. A. Murad, "Frequency Reconfigurable Epsilon Negative Metamaterial Antenna," International Journal of Electrical and Computer Engineering (IJECE), Vol 7, No 3: 2017

[9] Yongqiang Chen, Guo Huiping, Yang Xinmi, \& Liu Xueguan, “A low-profile dual-band RFID antenna combined with silence element," Proceedings of the International Symposium on Antennas \& Propagation, vol2, pp.1146$1149,2013$.

[10] Verma S. \& P. Kumar, "Dual-Band UHF-RFID Tags Based on Meander-Line Antennas Loaded with Spiral Resonators," IEEE Antennas and Wireless Propagation Letters, vol.10, pp. 768-771, 2011.

[11] Arnieri, E., Boccia, L., Amendola, G.\& Di Massa, G., "A Compact High Gain Antenna for Small Satellite Applications," IEEE Transactions on Antennas and Propagation, vol.55(2), pp.277-282, 2007.

[12] Bao, X. L., Ammann, M. J., Member, S., \& Mcevoy, P., "Microstrip-Fed Wideband Circularly Polarized Printed Antenna, "IEEE Transactions on Antennas and Propagation, vol.58(10) pp. 3150-3156,2010.

[13] Hsu, C.-W., Lin, S.-K., \& Lin, Y.-C., "Dual-frequency dual-sense circular polarization on asymmetric crosseddipole antenna," Proceedings of the 2012 IEEE International Symposium on Antennas and Propagation, pp. $1-2,2012$.

[14] Rajagopalan, H., J.M Kovitz, \& Y. Rahmat-Samii, "MEMS Reconfigurable Optimized E-shaped Patch Antenna Design for Cognitive Radio.," IEEE Transactions on Antennas and Propagation, vol.62 (3) pp. 1056-1064, 2014.

[15] Chen Yikai, Yang Shiwen \& Nie Zaiping, Bandwidth Enhancement Method for Low Profile E-ShapedMicrostrip Patch Antennas," IEEE Transactions on Antennas and Propagation, vol.58(7) pp. 2442-2447,2010.

[16] Nanbo Jin \& Y. Rahmat-Samii, "Design of E-Shaped Dual-Band and Wideband Patch Antenna Using Parallel PSO/FDTD algorithm," IEEE International Symposium on Antennas and Propagation Society, vol.2A, pp.37-40, 2005.

[17] Khidre, A., Lee Kai-Fong, Fan Yang \& A.Z. Elsherbeni, "Circular Polarization Reconfigurable Wideband EShaped Patch Antenna for Wireless Applications," IEEE Transactions on Antennas and Propagation, vol.61 (2), pp. 960-964, 2013.

[18] Zaman, M. R., Islam, M. T., \& Kibria, S., "A Novel U-Shaped Parasitic Asymmetric Microstrip Cap Loaded Compact Patch Antenna,” ACES Journal, vol.30 (2), pp.191-203, 2015. 